\title{
Towards improved standardization of electricity meter testing
}

This paper was downloaded from TechRxiv (https://www.techrxiv.org).

\section{LICENSE}

CC BY 4.0

SUBMISSION DATE / POSTED DATE

$21-12-2020$ / 30-12-2020

\section{CITATION}

van den Brom, Helko; Rietveld, Gert; Hoogenboom, Dennis; van Leeuwen, Ronald; Marais, Zander; Sharma, Samriddh; et al. (2020): Towards improved standardization of electricity meter testing. TechRxiv. Preprint. https://doi.org/10.36227/techrxiv.13469622.v1

$\mathrm{DOI}$

10.36227/techrxiv.13469622.v1 


\title{
Towards improved standardization of electricity meter testing
}

\author{
H.E. van den Brom, G. Rietveld, D. Hoogenboom, R. van Leeuwen, Z. Marais, \\ G.J.P. Kok, S. Sharma and M.G.A. van Veghel \\ VSL, Delft, The Netherlands \\ hvdbrom@vsl.nl
}

\begin{abstract}
This paper describes present research towards improved standardization of static electricity meter testing with conducted electromagnetic interference (EMI). The latest experiences distilled from this research are presented regarding waveform capturing and advanced testing.

Index Terms - Energy measurement, electromagnetic compatibility, measurement errors, electricity meters.
\end{abstract}

\section{INTRODUCTION}

The energy reading of some static electricity meters seem to be sensitive to specific conducted electromagnetic interference (EMI), showing errors up to several hundreds of percent [1]. An independent investigation using traceable measurement equipment, performed on a more extended set of static meters, confirmed these earlier findings [2].

The observed sensitivity of electricity meters to this specific conducted EMI suggests that the present harmonized standards are not sufficient to prove that the meters currently being rolledout fulfill their accuracy limits under real operating conditions. In this paper, we describe research towards improved standardization of meter testing, including the experiences distilled from actual testing.

\section{MEASUREMENT OF STATIC METER ERRORS}

\section{A. Summary of Original Meter Error Findings}

Over 50 static electricity meters have been tested using a power supply and a set of loads. Voltage and current waveforms are captured using high-speed digitizers in combination with a wideband shunt and a voltage divider [2]. The most disturbing loads consist of a phase-firing dimmer in combination with LED and CFL lamps, resulting in highly distorted wideband current waveforms with significant frequency content up to $30 \mathrm{kHz}$. Meters with Rogowski coils or Hall sensors appeared to be the most sensitive, although some meters using shunts or current transformers also showed error readings.

These early results initiated a joint European research project to evaluate the effects of conducted EMI on the error readings of static electricity meters [3]. This project aims to provide evidence and measurement techniques to resolve these large meter errors and to provide input for improved standardization.

\section{B. Current Waveforms from Household Appliances}

Initial criticism stated that the extreme signals in the early tests do not represent realistic household situations using CEmarked equipment. Therefore, a large series of waveforms resulting from common household appliances has been determined. The recorded waveforms were categorized in terms of their crest factor, maximum peak current and maximum current change per time interval $(d I / d t)$. The largest meter errors were found for loads causing large peak currents in combination with large $d I / d t$ [4].

In successive studies most of this equipment turned out to cause no error readings, even for a meter that proved to be most sensitive to conducted EMI in previous studies. The largest meter error was caused by a specific water pump with corresponding dimmer that was withdrawn from the consumer market afterwards because of a violation of EMC regulations despite its CE mark.

\section{Variation of Disturbing Load Parameters}

Reducing the input inductance of the phase-firing dimmer connected to a combined set of LED and CFL lamps caused the current waveforms to show more extreme distortions and most of the meter errors to increase, whereas increasing the inductance mostly reduced the meter errors significantly [5].

For lower input impedance values, the phase-firing angle was varied from zero (no dimming) to almost $120^{\circ}$. Most of the affected meters showed an error increasing with phase angle, but some showed negative errors for small angles and positive errors for large angles, with a minimum around $90^{\circ}$. As expected, meter errors were found to be reproducible with repeated application of the same disturbing load even in the presence of additional linear loads.

\section{Capturing of Distorted Waveforms}

In real households usually a variety of equipment is loading the mains supply, resulting in a complicated current waveform. An on-site meter was developed to record potentially harmful waveforms and to serve as a benchmark meter in case of disputes between end users and utilities. When recording waveforms at high sampling rate, a trigger mechanism should be used to avoid an overflow of measurement data [6]. The onsite meter developed uses threshold settings for crest factor and $d I / d t$ to trigger waveform capturing. This meter is presently used to capture waveforms that occur in practical situations of end-users in the Netherlands.

\section{E. Advanced Testbed for Electricity Meter Testing}

For more systematic research and testing of electricity meters with conducted EMI, a testbed is developed that is able to generate and simultaneously measure high-speed waveforms 
representing highly distorted real-world signals as well as artificial test signals. To generate the steep-edge signals with the required rich harmonic content synchronized digital-toanalog converters are used in combination with separate wideband voltage and current amplifiers [7]. To validate this new testbed, a meter was used with very high error readings in earlier tests with real loads. The same waveforms were used as recorded in those earlier tests, and meter error readings were observed to be identical even for the most disturbing signals.

This validation shows that the testbed is suitable for testing electricity meters using any relevant waveform, including future standardized test waveforms and waveforms that might be useful for scientific research such as wavelet decomposition or other analysis of test signals [6].

\section{PRActical CONSIDERATIONS For TeSting}

From the research and tests of over 50 meters as described in the previous sections, several practical experiences can be distilled for future testing of electricity meters.

First of all, most studies describe errors in relative terms as a percentage of the "true" energy. Describing the errors in absolute terms appeared useful when comparing test results at different power levels, especially at very low power levels.

The power consumption of the meter itself should be corrected for when calculating the reference energy, especially for tests at low power levels and when testing several meters in series. Likewise, when using a resistive voltage divider to measure the voltage signal, the current drawn by the resistors should be considered as well. Relative positioning of the voltage divider with respect to the meter under test must be considered to reduce the influence of this leakage current.

When changing the power supply from a stand-alone laboratory power supply to the ordinary mains supply, the test waveforms change leading to significantly different error readings for some specific loads and meters. Consequently, for standardized electricity meter testing, the output impedance of the supply voltage should be standardized as well.

Meter error readings can be strongly dependent on the waveform details. When using real household appliances as a load, the waveform is not always constant in time. After recording 10 successive cycles (covering a time span of $200 \mathrm{~ms}$ ) for the water pump discussed earlier, all cycles were used as individual test waveforms using the testbed. The resulting meter error readings showed variations of up to $10 \%$.

Using the meter testbed, the effect of the voltage signal was investigated, and initial results show that even for the most disturbed current waveforms and for the most sensitive meter, the difference in meter reading error between applying the slightly distorted voltage waveform or a pure sine wave is negligible. Also, for current signals mimicking the slightly distorted voltage signal, no error was found, showing that the voltage signal is not causing the error reading.
It should be noted that the appliances showing the largest error readings are characterized by the fact that a dimmer is used to control the output power of the connected load resulting in large step-changes in current [2]. The settings and input stage of the dimmer has a huge impact on the meter errors.

\section{CONCLUSION AND FUTURE WORK}

The influence of specific conducted EMI on the energy reading of static electricity meters has been extensively investigated. The results obtained in this study can be used as future input for new test signals and measurement methods for type testing and for updating test standards for testing static electricity meters. The results need to be intensively discussed with standard development organizations, utilities, meter manufacturers and other stakeholders.

Present work concerns the definition of possible test waveforms for future standardization and a further validation of the VSL testbed by comparison to other testbeds developed by other metrology institutes.

\section{ACKNOWLEDGEMENT}

The work described in this paper is partially performed within the 17NRM02 MeterEMI project of the European Metrology Programme for Innovation and Research (EMPIR). The EMPIR initiative is co-funded by the European Union's Horizon 2020 research and innovation programme and the EMPIR participating states. Additional funding was received from the Dutch Ministry of Economic Affairs.

\section{REFERENCES}

[1] F. Leferink, C. Keyer, A. Melentjev, "Static energy meter errors caused by conducted electromagnetic interference," IEEE Electromagnetic Compatibility Magazine, vol. 5, Issue 4, pp 4955, Fourth Quarter 2016

[2] G. Rietveld, D. Hoogenboom and M. Acanski, "Conducted EMI causing error readings of static electricity meters", CPEM Conf. Dig., Paris, France, July 2018

[3] P.S. Wright, G. Rietveld, F. Leferink, H.E. van den Brom, F.R.I. Alonso, J.P. Braun, K. Ellingsberg, M. Pous and M. Svoboda, "Evaluation of EMI Effects on Static Electricity Meters", Conference on Precision Electromagnetic Measurements, Paris, France, 8-13 July 2018

[4] R. van Leeuwen, H. van den Brom, D. Hoogenboom, G. Kok, and G. Rietveld, "Current waveforms of household appliances for advanced meter testing”, AMPS, Aachen, Germany, Sept. 2019.

[5] Z. Marais, H. van den Brom, G. Rietveld, R. van Leeuwen, D. Hoogenboom, and J. Rens, "Sensitivity of static energy meter reading errors to changes in non-sinusoidal load conditions", EMC Europe, Barcelona, Spain, Sept. 2019.

[6] F. Barakou, P. Wright, H. van den Brom, G. Kok, and G. Rietveld, "Detection Methods for Current Signals Causing Errors in Static Electricity Meters", EMC Europe, Barcelona, Spain, Sept. 2019

[7] H. van den Brom, Z. Marais, D. Hoogenboom, R. van Leeuwen, and G. Rietveld, "A Testbed for Static Electricity Meter Testing with Conducted EMI”, EMC Europe, Barcelona, Spain, 2019. 